Authenticity, Innovation and the Geographical Indication in an Artisanal Industry: The Case of the Banarasi Sari

Amit Basole

WORKING PAPER 2014-09

DEPARTMENT OF ECONOMICS

UNIVERSITY OF MASSACHUSETTS BOSTON 


\title{
Authenticity, Innovation, and the Geographical Indication in an Artisanal Industry: The Case of the Banarasi Sari
}

\author{
Amit Basole \\ Department of Economics, University of Massachusetts, Boston, MA
}

Artisanal industries contribute significantly to employment, output, as well as export earnings in developing countries in addition to being bearers of cultural identity (Nash 1993; Liebl and Roy 2004). But despite producing high-value added products with skilled labor, artisans usually work in the "informal sector" under precarious working conditions and for low wages due to a subordinate position in the value-chain (Scrase 2003; Basole and Basu 2011). Their livelihoods are further threatened by commercial imitation and passing-off of mechanized products as craft (Fowler 2004). Recently, there has been a lot of interest in improving artisanal livelihoods and preserving crafts via participation in global markets. ${ }^{1}$ International institutions such as the World Bank and the World Intellectual Property Organization have proposed the integration of artisanal knowledge into existing intellectual property regimes as the solution to creating brand identity, discouraging imitation, and enhancing incomes (Finger and Schuler 2004; WIPO 2008).

This debate is part of a broader discourse on how (and whether) traditional and indigenous knowledge $(\mathrm{TK} / \mathrm{IK})$ can be protected within the institutional framework of international trade and intellectual property rights (Gervais 2005; Arewa 2006; Drahos 2011; Frankel 2011a,b). Several scholars and policy-makers have proposed Geographical Indications (GIs) as the preferred IPR to integrate TK/IK into the global market (Gopalakrishnan et al 2007; Aylwin and Coombe 2010; Das 2010; Martens 2012). The GI is an IPR that tends to favor existing methods of production over innovation and change (Hughes 2006; Drahos 2011). For this reason and due to their place-based and collective nature GIs are seen as compatible with local, community-based TK/IK, and have been hailed as "poor people's intellectual property rights" (Sunder 2007, p.114). Development agencies such as the United Nations Conference on Trade and Development (UNCTAD) have aggressively pushed for Geographical Indications and 
over the past ten years more than 400 GIs have been issued in India to various agricultural and artisanal products. ${ }^{2}$ Alwyn and Coombe (2010, p. 754) note that the IP "frenzy" in India is part of a trend in developing countries.

In this paper I ask under what conditions GIs can be the answer to the problems of poor but skilled artisans in developing countries, and what are their limitations in doing so. I address these questions using the case of the centuries old artisanal weaving industry located in the Indian city of Banaras (Kumar 1988). The industry was granted a GI in 2009 for its embroidered, hand-woven, silk fabrics (Banaras Bunkar Samiti et al 2009). I argue that GIs, in order to be effective, must be designed through a participatory process in which ordinary artisans, who are the producers of knowledge in any tradition, are closely involved. Further the GI must be sensitive to the dynamic nature of artisanal knowledge. Finally, I also argue that a GI cannot address problems that arise out of the political economy (power relations) of artisanal industries.

The Banaras textile industry employs over 200,000 workers in weaving and allied activities, with a Rs. 30,000 million (approx. \$500 million) annual turnover (Varman and Chakravarti 2011). Its specialty is the Banarasi sari, ${ }^{3}$ hand-woven silk fabric with intricate woven embroidery worn by women (see Figure 3). Despite the industry's reputation within India and abroad, ordinary artisans who weave the fabric have been facing poverty and destitution due to falling demand for handloom products, excess supply of skilled labor, lack of employment alternatives, and capturing of value by traders (Ahmad 2007; Bose 2007; Basole 2014). The industry has faced stiff competition from other weaving centers in India and from China. In particular, the practice of passing-off machine-made fabric as hand-made has instigated attempts to formalize the definition of authentic Banarasi fabric via a GI that sets out detailed conditions a product must meet in order to qualify as Banarasi.

This study draws on surveys and interviews, as well as observations, resulting from fieldwork conducted between October 2009 and June 2010. ${ }^{4}$ Weavers, master-weavers merchants, NGO workers, and government officials were interviewed. I show how artisans conceptualize authenticity and contrast it with the way authenticity has been 
embodied in the GI. I also argue that the GI has been developed without significant participation of the artisanal community and is "preservationist," i.e. freezes current production methods in the name of craft preservation. In contrast artisans take a dynamic approach to their knowledge and innovate in response to market pressures as well as changing resource bases. A GI that seeks to preserve artisanal traditions, as they exist now, risks punishing artisans for innovating. To prevent this from happening, criteria of authenticity must be developed from within the artisanal community. I conclude that instead of allowing innovation and improving the distribution of value within the industry, the Banaras GI will discourage innovation and allow mal-distribution of value.

Secondly, I argue that a GI is not the solution to problems that result from the political economy of the artisanal value chain. As is well known, many artisanal industries are informal in nature and are organized on a "putting-out" basis. Artisans tend to have low bargaining power in product as well as labor markets in comparison to mastermanufacturers and merchants (Knorringa 1999; Scrase 2003; de Neve 2005; Basole and Basu 2011). As a result the distribution of value in national and global chains is biased towards merchants and traders. In extreme cases a ratio of 70:1 may exist between retail prices and the artisan's wages (Liebl and Roy 2005). In these circumstances, an effectively implemented GI can increase premiums in the market, but cannot ensure that these increases trickle down to the artisans. Further, unequal distribution of power in the value-chain can result in a subversion of the GI to suit more powerful interests in the industry (Gade 2004; Bowen and Zapata 2009).

The rest of this paper is organized as follows. In the next section I review the literature on traditional knowledge, the geographical indication, and artisanal industries. Next, taking the case of Banaras I show the context in which the GI has been issued. Following that I analyze the shortcomings of the GI in terms of process, content, and political economy. The final section discusses the way forward and concludes.

\section{Political Economy, Artisanal Knowledge and Intellectual Property Rights}

TK, GI, and Artisans 
The coming of the "Knowledge Society" has meant unprecedented attention for previously neglected traditions of knowledge, particularly in developing countries. Traditional and Indigenous Knowledge (TK/IK) systems have been studied for their content, value system, epistemology, and poverty reduction potential (Warren et al 1995; Sillitoe et al 2002; Woytek et al 2004). Property rights in TK/IK have been advanced as a mechanism to prevent "biopiracy" and to ensure that knowledge-producing communities share in material benefits that accrue from commercial applications of their knowledge (Subbiah 2004; Arewa 2006). The World Trade Organization, though its Trade Related Intellectual Property Rights (TRIPs) regime and the World Intellectual Property Organization (WIPO), along with law and development scholars have engaged with the question of how TK/IK systems should be reconciled with international IPR regimes. ${ }^{5} \mathrm{~A}$ powerful idea has emerged that "poor people's knowledge" can be an asset in the global market if properly commodified and that IPRs in TK/IK can ensure that the international IPR systems works for the poor (Cottier and Panizzon 2004; Finger and Schuler 2004).

A type of IPR that has received the most attention in this context is the Geographical Indication (GI). ${ }^{6} \mathrm{TK} / \mathrm{IK}$ is usually collectively owned by a community (though the concept of ownership may differ from the modern/Western sense) and is not the property of individuals or firms. The knowledge also tends to have a strong local dimension and bears cultural significance for its holders and for society at large. Hence a place-based, collective IPR such as the GI has been deemed suitable for the purpose of granting legal protection to this knowledge (Downes 1997; Cottier and Panizzon 2004; Das 2007; Martens 2012). A GI is expected to prevent misappropriation and counterfeiting (passingoff), and provide an economic premium in the global market. Further, as evidenced by the long history of marks indicating conditions of origin (MICOs) for European wines and cheeses, in addition to signaling that a product truly originates in a particular geographic region, such an IPR is designed to preserve a "culture of production" as well as a "culture of consumption" and most GIs have been granted to commodities with a cultural significance (Broude 2005, p. 654). Addor and Grazioli (2002, p. 866) also argue that GIs are based on collective traditions and a collective decision-making process and they "protect and reward traditions while allowing evolution." The hope is that the 
collective nature of the IPR will ensure that "economic benefits of GIs extend to all individuals and groups in the community who subscribe to the traditional practices belonging to the culture of that community" (Dagne 2010, p. 101).

Since their formalization as a part of TRIPs in the early 1990s, GIs have become increasingly popular among international development agencies, non-governmental organizations (NGOs), policy-makers, and academics as a means of protecting traditional knowledge and developing brands for TK-based exports (Rangnekar 2010). In India sui generis legislation was passed (as The Geographical Indications Act 1999) as part of the effort to have intellectual property laws be compatible with TRIPs (Gopalkrishnan et al 2007). ${ }^{7}$ The first GI was awarded to Darjeeling Tea in 2003 (Das 2006). As of May 2014 (the latest data available) 482 GIs have been awarded, of which 224 are for artisanal products. Many more could potentially be awarded since India has thousands of living artisanal traditions in textiles, food products, metal products, household consumer goods, jewelry and so on (Soam 2005).

\section{Criteria of Authenticity and Innovation}

The allure of a GI-based approach to supporting artisanal industries can also be understood through the perspective of the creation of an authentic craft product. Official as well as consumer attitudes towards artisanal products are often shaped by what I term a "preservationist" paradigm that sees artisanal knowledge as fixed or even antiinnovation. A producer is rewarded for conforming to the notion of what constitutes "authentic craft" and is discouraged from innovating. Venkatesan (2009) recounts such an incident. Fatima, a mat weaver from Pattamadai in the southern Indian state of Tamil Nadu, decided to weave what she considered a "special mat" for a craft awards competition in New Delhi. She chose to weave a picture of the Taj Mahal in bright colors (pink, green blue) on the mat. The mat did not win an award and the head of the Tamil Nadu State Handicrafts Emporium commented on it as follows: "who would pay money for that! It is too modern and bright, not like an authentic Pattamadai mat." (p. 136). After recounting one more similar story, Venkatesan concludes that "the craft weaver's own 
aesthetic is disregarded when it does not conform to this larger vision of what the craft object ought to look like" (p. 137).

As per the preservationist view, the criterion for considering art or craft authentic is not its originality but rather the lack thereof, i.e. the quality of looking identical to other objects that fit the stereotype (Steiner 1999). Objects are considered to be ethnographically authentic if "they accurately represent a bounded, named culture, cultural group, or cultural identity" (Field 2009). Of course this very process of creating authenticity also creates scope for imitation. For example, since "everyone knows" what an authentic Navajo rug looks like, the appearance can be easily mimicked. Indeed several "Native American" artifacts sold to tourists in the United States are produced in China, the Philippines and other Asian countries. ${ }^{8}$

In this context, an IPR like the GI emerges as the legal mechanism through which products can be standardized as well as protected. A product becomes eligible for a GI not only by virtue of where it is produced, but how, and compliance with a strict set of criteria is often a key component of the right to use the GI. The state bureaucracy behind the GI usually requires GI-holders to conform to a strict set of rules (well-studied in the case of the French appellations de origins for wine) and determines what constitutes authentic knowledge (Chan 2011). While discussing the Denomination of Origin granted to Chulacanas Pottery of Peru, Chan relates an interesting incident. Speaking at a UNsponsored conference on "Folkart, Innovation, and Sustainable Development," Peru's National Director of Folkart emphasizes the importance of making a genuine "native product." After asserting that artisans themselves will decide what their product is, she elaborates that such a product should use local, regional materials and integrate "ancestral" techniques in its elaboration. If there is a contradiction between letting artisans decide what constitutes an authentic product and also simultaneously laying down the conditions for authenticity, the Director seems oblivious to it. The condition for participating in the global niche markets is thus that criteria of authenticity become external to the craft community and are delivered in a top down fashion. The "GI protects 
the name for use by those whom the associated bureaucracy deems to merit its use." (Frankel 2011b, p. 260)

This last point is significant because it raises the issue of how such criteria are decided and what are the epistemological premises that guide thinking on traditional knowledge. Frankel (2011b, p.261) observes that "there is frequently a suggestion that tradition and not innovation lies with the holders of the knowledge and the innovation is that of the modern users." Thus there appears to be an affinity with GIs that are often thought of as conservative IPRs designed not to spur innovation but to preserve certain practices. ${ }^{9}$ But note that the uniformity or predictability of craft products is not in fact the result of stagnant or unchanging "traditional knowledge." Rather it is produced via bureaucratic as well as market-imposed standardization that is a condition for participating in national and transnational economic and cultural flows (Chan 2011).

Indeed the dangers of overly restrictive standardization have been raised in the literature on GIs. Das (2010, pp. 164-65) recognizes the double-bind between creating standards for authenticity and stifling innovation:

Quality control and enforcement calls for establishment of an effective regulatory mechanism, preferably comprising third parties. However, the flip-side is that stringent standardization and quality control may often end up imposing detrimental rigidities in the system, hindering its ability to accommodate innovations and experimentations in line with technological development as well as change in consumer tastes and preferences.

French winemakers, for example, have complained about the innovation-inhibiting nature of the bureaucratic control systems associated with the appellation de origin (Hughes 2006). And Drahos (2011, p. 247) notes that "a GI system can have a lock-in effect when it comes to traditional methods of production, acting as an incentive against innovation." 10

Most close observers of TK/IK disagree with the position that these knowledge systems are anti-innovation. Scott (1998, p. 331) asserts that the term "traditional" sends out "all 
the wrong signals" and that "a certain understanding of science ...has so successfully structured the dominant discourse that all other kinds of knowledge are regarded as backward, static traditions..." He offers examples of how quickly "traditional peoples" incorporate new knowledge that solves problems. Similarly Dickie and Frank (1996, p. 52) observe that, even seemingly "traditional" crafts may be a recent innovation and Frankel (2011b, p. 262) offers more examples of the dynamism of TK. ${ }^{11}$

Sahasrabudhey and Sahasrabudhey (2001) have coined the term "lokavidya" (lit. people's knowledge) to escape the static connotations of "traditional knowledge." This knowledge, which is neither traditional (in the sense of being unchanging or un-touched by modern techniques) nor modern (in the sense of being acquired in modern institutions), is ubiquitous in developing countries where the vast majority of the working population has acquired its knowledge and skills "on-the-job" through various kinds of apprenticeshipbased methods (Basole 2012). It is generated and maintained through contemporary practice. It constantly evolves and does not seek to tie people to ways of knowing and doing of the past. Here the question of preservation of craft authenticity is moot. This does not mean that standards of production are absent. Rather such standards and criteria are developed by the community of producers in continuity with their own tradition, together with market considerations, not merely by considerations of craft preservation.

Changes in production technology (mechanization in particular) pose a challenge for GIbased craft authenticity. In agricultural products, such as Argan oil from Morocco or coffee from Costa Rica, the issue of mechanization is not important (hand pressed versus machine pressed oil, sun dried versus machine dried coffee) because the product is defined through its origins in the soil. Thus technical change can occur within the framework of the GI. But for handicrafts, the product is defined through the production technology. As such one effect of a GI may be to freeze the technique. This may reinforce one of the key supply-side constraints in the Indian craft sector identified by Leibl and Roy (2005), viz. lack of technical innovation (labor-saving methods). This study deals with one such instance, the switch from hand-weaving to machine-weaving. 


\section{Political Economy}

In the preservationist view, the artisanal community is treated as homogenous or it is assumed that premiums resulting from the GI will be shared equitably within the community. But the reality is far from it. Larger manufacturers and traders are usually the more powerful actors in a craft value chain and only a small part of the retail value of a craft product makes its way to the actual producers, the artisans (Knorringa 1999; Scrase 2003; Liebl and Roy 2004; de Neve 2005; Basole and Basu 2011). This problem is hard to tackle within an IPR framework. Gopalkrishnan et al (2007) in their comparative study of Asian GIs note that most of the countries studied include traders in the definition of producers and allow them to be treated as owners of the GI. Since traders tend to have more capital and also greater market power (usually due to being far fewer in number than artisans) in most traditional industries, this raises the question of how the local political economy will shape the use of the GI.

In such circumstances, even worse than allowing no innovation, those changes to the product may be allowed which suit the interests of larger producers or traders at the expense of smaller producers. Bowen (2010) finds in the case of Tequila that over time influential actors in the supply chain manipulated GI production standards and certification policies to benefit themselves and undermine the quality of the product. For example, larger tequila companies successfully lobbied the Mexican government to reduce required proportion of Agave in the liquor from $100 \%$ to $51 \%$ to the detriment of the small farmers who produce the agave. Similarly Gade (2004) shows that the Appellation of Origin granted to Cassis in Southern France has shrunk to be controlled by a small syndicate that changes the allowed conditions of production to suit the convenience of its members even as it limits the types of vines that can be used, thereby restricting the number of producers. Aylwin and Coombe (2010, p. 779) summarize such critiques into the more general point that "producers with the most secure marketing networks [and one might add, the most capital] tend to secure the lion's share of the values" that GIs yield. If the problem was that in the absence of formal criteria more powerful actors are able to take advantage by passing-off imitation products as real products, then it is also possible that formal criteria created via un-participatory processes 
may not solve any of these problems, but rather may create new ones by shutting out genuine producers on various pretexts.

The Indian handloom industry is a case in point. India is home to hundreds of distinct hand-woven products, many of which have already been awarded GIs (indeed the sector has been called a "gold mine of geographical indications" by Vinayan (2012)). A principal reason for awarding an IPR to the handloom industry is to prevent competition from the decentralized mechanized weaving sector (called "powerlooms" in India). But in many instances, the growth of powerlooms has occurred endogenously with capital accumulated in handloom. State policy has also favored powerloom over handlooms. ${ }^{12}$ Existing legislation that protects the handloom market (such as the Handloom Reservation Act, 1985) and certification schemes such as the Handloom Mark, whose intent was to prevent passing-off of machine-made cloth as hand-made, have largely failed due to corruption and complicity of government officials with powerloom producers (Srinivasulu 1996; Vinayan 2012). In these circumstances, it is unclear how much impact a GI would have in reviving handloom production.

I now turn to the case-study of the artisanal weaving industry in Banaras to investigate the above issues in a concrete empirical context.

\section{Authenticity, Passing-off and the GI in Banaras}

\section{The Industry and its Product}

The city of Banaras (officially Varanasi) is situated on the banks of the river Ganga in the eastern part of the state of Uttar Pradesh in north India. The city is well known for its religious significance for Hindus and is also the site of a large weaving industry composed largely of Muslim artisans (Kumar 1988; Raman 2010, 2013). Though precise statistics are not available, there are an estimated 60,000-100,000 handlooms and over 40,000 powerlooms in the city. Counting allied occupations such as dyeing, embroidery

etc., the population connected with the industry probably numbers in the several hundred thousands. Though identified with Banaras city, the product is manufactured in surrounding rural areas and smaller towns in Varanasi district as well as in surrounding 
districts. The annual turnover is Rs. 30,000 million (approx. \$500 million). However, despite its size and reputation, the industry has been the subject of few scholarly studies. $^{13}$

A primer on the industry's organization is necessary before we begin. The following account draws on Government of India (2008) and Basole (2014). Figure 1 is a schematic depiction of the main actors in the industry. The hand and power segments of the industry are organized along similar lines. There are three types of weavers: loomless weavers who weave in the employer's home or workshop, job-workers who work in their own home for a master-weaver and typically own their looms, and own-workers who own their looms and produce for direct sale on the wholesale market in Banaras. Women perform allied tasks such as winding or warp. Both job-workers and own- workers may also employ a small number of loomless weavers if they have idle loom capacity and if there are demand pressures.

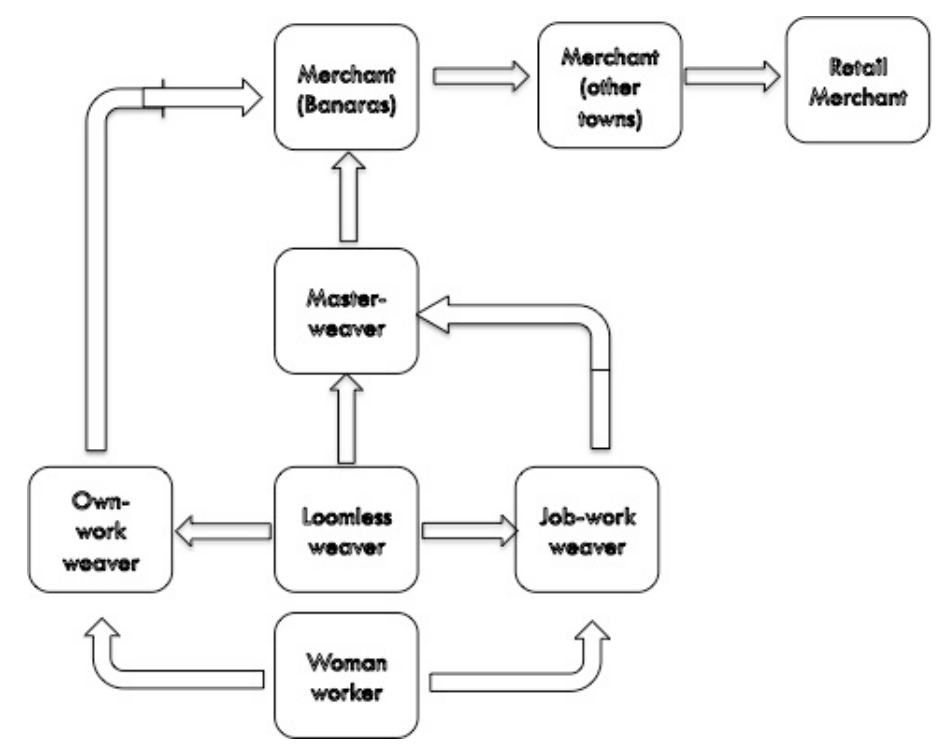

Figure 1: Organization of the Banaras Weaving Industry

Source: Author

Master-weavers are own-workers with enough capital to produce in-house, as well as put work out to a variable number of job-work weavers and/or employ loomless weavers on their premises in exchange for piece-wages. Own-workers as well as master weavers sell 
finished products to merchants or traders in the wholesale market located in the city center. Nearly $90 \%$ of total production is sold in the city itself. Production has traditionally been home-based though small workshops are emerging particularly with powerlooms. Small-scale, non-random surveys reveal that a typical weaver has two to three hand or powerlooms in his home. The preferred mode of expansion is for masterweavers to put out work to a larger number of home-based units. There appear to be somewhere around 2000 master-weavers in Banaras city (Varman and Chakravarti 2011). Living standards are low among loomless, job-work, and small own-work weavers with daily incomes in the range of \$5-6 in PPP terms. Around 10\% of the final retail value of the product accrues to the weaver in the form of wages.

Figure 2 schematically depicts the four principal production decisions involved in making Banarasi fabric: the type of yarn to be used, the nature of the weave, weaving technology, and the type of design to be woven. In interviews weavers most often mentioned silk yarn and handloom technique as markers of authenticity. In addition some mentioned brocade (weft-based) embroidery, in which extra weft threads are introduced at specific places to create a pattern within the weave (Figure 3). The extra-weft may be introduced by throwing an extra shuttle from end to end (called a lance weave), in which case a pattern like the one shown on the right in Figure 3 is produced, or by passing the weft yarn under the warp only in sub-regions of the warp (a broche weave), which produces localized woven embroidery (Figure 3, left).

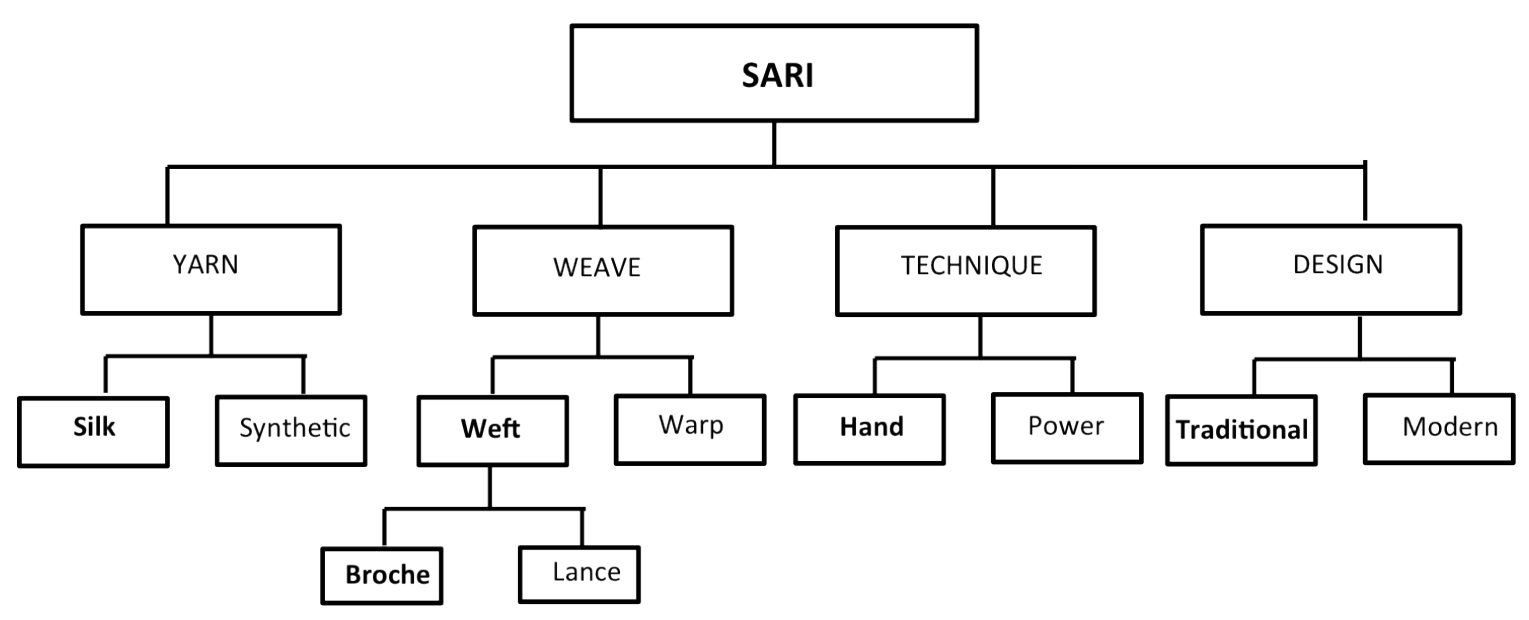


Figure 2: Banarasi Sari- Authentic versus Imitation

Source: Author

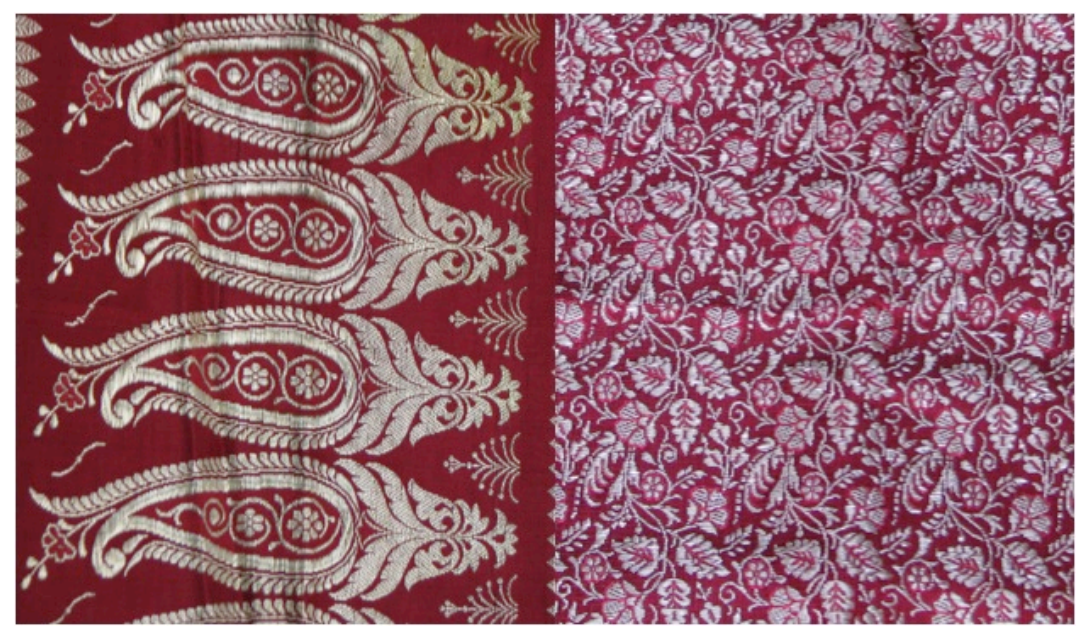

Figure 3: Examples of Banarasi brocades woven broche (left) and lance (right) Source: Field Photos.

Banarasi fabric is thus associated with the following three principal features: it is made of silk (silk warp and silk weft) on a handloom, and has brocade embroidery. Finally, there is a repertoire of patterns (locally known as "designs") that are traditionally recognized to be Banarasi. The bolded options in Figure 2, thus together constitute the commonly accepted definition of authentic Banarasi fabric. These are also the characteristics that have been formalized in the Geographical Indication.

\section{Crisis and the Geographical Indication}

In order to understand the context in which the GI was issued in 2009, it is necessary to appreciate the recent history of the industry. Academic, policy, and popular literature on the industry in the past decade is dominated by the narrative of "crisis." Industry observers and NGO workers believe that tens of thousands of weavers have either left the trade (to become rickshaw-drivers, vegetable vendors, carpenters and so forth) or have departed for weaving centers in Western India. Hunger and malnutrition deaths among 
children have been documented as have suicides due to debt and poverty (Bose 2007). ${ }^{14}$ Raman $(2010,2013)$ has dealt with this issue in detail and estimates that the industry has been troubled since the mid-1990s though the crisis acquired full-blown proportions only by 2003 or so. The principal cause identified in this literature is unfavorable trade policy that kept imported silk yarn from China expensive while cheap silk fabric from China and elsewhere in India such as Surat in Gujarat, flooded the market, passing-off of powerloom-made cloth as handmade. ${ }^{15}$ The increased availability of technology that can quickly digitize and transmit fabric patterns has made passing-off much easier in the last few years (Rashid 2014).

The crisis has brought about large changes in the industry's products. In order to compete, master weavers and traders in Banaras have resorted to unethical strategies such as depressing wages, compromising on quality of designs and dyes, and most significantly for our purposes, passing-off synthetic fibers for silk and powerloom fabric as handloom. Thus although Banarasi fabric is closely identified in the popular imagination with the characteristics discussed in the previous section, over the past few decades each of the four aspects of production, viz. yarn, weave, technology, and design has undergone large changes. A rise in the price of silk yarn has led weavers to substitute synthetic fibers such as viscose or nylon for silk. Broche supplementary weft weave (a specialty of the Banaras style), which requires two people, the weaver and an apprentice or assistant, has given way to the relatively less labor-intensive lance weave which can be managed by one person. But the most significant change has been the substitution of powerlooms for handlooms.

To restore the market for the "authentic Banarasi Sari" a campaign to issue a Geographical Indication was started in $2006 .{ }^{16}$ A key actor in the entire process from making the demand for a GI to writing the application was a local NGO, the Human Welfare Association (HWA) that ran a campaign against Chinese silk fabric imports to raise awareness on the issue. HWA was aided financially by UNCTAD which has taken the lead, at the national level, in promoting the GI to local agencies and organizations. A GI in the name of "Banarasi Saris and Brocades" was awarded in 2009. The geographical region in question is not only the city of Banaras, but a larger area consisting of five 
districts of the state of Uttar Pradesh, viz. Varanasi (Banaras), Chandauli, Bhadohi, Mirzapur and Azamgarh.

In the remainder of the paper I discuss three dimensions of the Banaras GI that I believe have relevance for artisanal GIs in general. I examine the process by which it was developed, how it treats artisanal knowledge, and what its effects may be given the political economy of the industry. The data for this article was collected the same year that the GI was awarded. Hence the impact of the GI on artisanal incomes will be subject of future studies.

\section{GI Process, Content, and Political Economy}

\section{The GI Process}

Although UNCTAD claims to follow a "bottom-up" approach wherein it does not file an application on its own, but rather encourages artisans to file it themselves, the bottom-up aspect appears to be weak in the case of Banaras. The application was made by nine organizations, known in GI terminology as "Registered Proprietors." ${ }^{17}$ Of these two are NGOs (one being a self-help group set up by the other), two are governmental agencies, two are traders' organizations and the remaining three are producer cooperative societies. While this list appears to be a broad cross-section of interest groups in the industry, ordinary weavers who have contributed most to the knowledge commons that the GI seeks to brand and protect, are missing from this picture. The NGOs only work with a small number of rural Hindu weavers while the majority of weavers is city-based Muslims. The trader organizations represent the merchants in the wholesale business whose interests have traditionally been opposed to the majority of weavers who work on piece-wages. The governmental agencies are seen in Banaras as being very much external to the artisan community and do not have a presence in the artisan neighborhoods. Most ordinary weavers are deeply cynical of official efforts to help the industry due to long experience with corruption and mismanagement of welfare schemes. Finally, the producer cooperatives that should be the legitimate representatives of the weavers have long ceased to perform this role in Banaras having been captured by the large master- 
weavers who run the co-ops in the name of their employees or under fictitious names (Ahmad 2007; Government of India 2008). ${ }^{18}$

The key actor in the GI process was the NGO, HWA, whose representatives attended UNCTAD meetings in New Delhi in April-May 2006. Following these meetings, on May $12^{\text {th }}, 2006$ a "sensitization workshop" took place in Banaras. The attendee list, as reported in the HWA newsletter, makes it clear that the workshop was dominated by government officials and traders/exporters. The location of the workshop (a hotel removed from the weaver localities) also indicates that this was not an event under the control of the artisanal community. The director of HWA Dr. Rajnikant admitted that he had to contend with his outsider status among the Banaras weavers:

For the GI we had to struggle for two and a half years. Local people in Banaras opposed us. They said "Who are Dr. Rajnikant and HWA to get the GI registration? We have been working for so many years, we are not applicants." (Field Interview 11/14/2009).

He emphasizes that he attempted to address such concerns by explaining the nature of the GI.

They did not understand the GI. They thought this will become my property. They did not know that it is for all producers in this geographical area and that we are simply the petitioners. When they realized, they appreciated it and they joined us (ibid).

But no broad-based community-wide consultations seem to have been held. Hence it is not surprising that the vast majority of weavers and master-weavers I spoke with in the period between December 2009 and June 2010 were not even aware of the existence of the GI, fully three years after the campaign was launched. Thus one of the two preconditions identified by Liebl and Roy (2004, p. 65) for the success of a GI, viz. "strong collective bodies at the local level," seems to be conspicuous by its absence in the case of Banaras. As a result the criteria and standards outlined in the GI have been developed without substantial community participation. Incidentally and not unrelatedly, the text of the application is entirely in English, a language that a negligible proportion of weavers can read. 
Further, the law places the same non-representative organizations in charge of controlling access to the GI. In order to be able to make use of the GI mark legally a producer must become an "authorized user." For this a legal application has to be made to the GI Court in Chennai (in South India) together with a letter of consent (or "No Objection Certificate") from a registered proprietor. Dr. Rajnikant describes the process as follows: They will need a No Objection Certificate from us...After we give the letter the court verifies the application and there is a hearing... first you have to prove that you work with handloom, maybe a photo ID, or if you are member of a co-op etc. You need all the papers and affidavit, a power of attorney is needed...If the judge feels there is a need to do a field visit he will, otherwise he will grant it. ${ }^{19}$

The small own-work handloom weavers who could benefit from the GI are likely to find the registration process onerous. One handloom weaver commented:

It is good that there is a patent (English word in original). But now if you are a weaver, you need a photo, an identification card, and patent number. You need to attach a sample sari. Then you have to answer questions, is it your product, where did you get it from, who did you sell it to, everything has to be entered. It is very difficult. A trader could do it, but a worker doesn't want to deal with so many complications. He wants wages. (Field Interview 4/28/2010)

Another disturbing possibility is that those producers who have not secured the "authorized user" status under the GI Act, either because they cannot afford the time and money that goes into the application process or because they lack information, will be in legal infringement of the GI if they call their product "Banarasi." Although the wording of the GI Act does not indicate this to be a possibility, some comments to this effect appeared in the local press soon after the GI was issued, creating confusion (Field Notes $4 / 28 / 2010) .{ }^{20}$ In response to the question does the GI automatically extend to producers who have not become authorized users, Abhijit Das, of UNCTAD India clarified:

If I stay in the area of Banaras and produce handwoven Banarasi saris and brocades, even if I am not a registered user, I still can use the GI tag, till someone 
legally complains... of course there is no denying the fact that being a registered user ensures 100\% legal certainty (Field Interview 6/9/2010).

The operative phrase in the response is "till someone legally complains." Even if such a complaint is unlikely, the possibility cannot be ruled out that such a law provides an opportunity for harassment, and that changing legal entitlements will influence informal practice and negotiation. ${ }^{21}$ Without a strong community-based organization backing him a small weaver would have very little standing or capacity to deal with such litigation. Finally, the vast majority of poor weavers, who are either loomless or work on contract for master-weavers, have no role in this process. For them the benefits of the GI, if any, would be trickle-down effects of an increased market share for their master's products.

\section{Artisanal Knowledge and GI}

The implication of the process by which the GI was developed is that its vision of what is authentic Banarasi fabric clashes with the actual dynamics of knowledge production in the industry. Interviews with as well as press statements of the key actors in the GI process reveal that the problem of weaver livelihoods is conceived in terms of the preservation of what is understood by NGOs and government agencies to be their authentic craft. The GI application catalogs current practice in great detail, describing eleven types of fabrics that are considered Banarasi. Silk yarn and handloom technology are the defining elements of all types. For each type of fabric the dimensions, the reed and pick (number of warp and weft threads per centimeter), the type of yarn and the type of weave are defined. Each design or pattern is described. For example, the famous Jangla ("forest") pattern:

The border is $11.7 \mathrm{cms}$. wide including a selvedge of $0.7 \mathrm{~cm}$. It consists of a central panel of $5 \mathrm{~cm}$ flanked by stripes of a plain line, parallelogram blocks, one line, a decorative panel, one line, parallelogram blocks and two lines in order, on either side, on a mauve ground... One of the leaves and the inner petals of the flower are in extra-weft silver thread worked by the broche technique and the rest in extra-weft gold thread woven by the lance technique. (Banaras Bunkar Samiti et al. 2009, p.34) 
While this may be a faithful description of current practice, such rigorous standardization seems unnecessary and could hurt the evolution of the product. It also does not capture the fluidity of designs. Jyotindra Jain, former Director of the National Crafts Museum and an authority on Indian crafts, warns that over-standardization of designs and materials in crafts could be detrimental to innovation. Further, he points out that designs and technical knowledge are a collective heritage and the large number of permutations and combinations of motifs that go into designs are difficult to register for copyrights or patents (Email Interview, 6/26/2011). In Banaras, for example, fabric patterns have been produced by artists over generations, adding incrementally to the existing pool via a ceaseless process of imitation and innovation. Designs are not copyrighted to individuals (Basole 2014). "Traditional” design motifs, the kairi (paisley), buti (small florals), buta (large florals), bel (vine), etc. have been modified and blended over the decades with more modern designs and have been simplified to suit modern tastes and production techniques (Cort 1980).

A piece of knowledge such as the Jangla design is a result of an organic process of incremental innovations over a long period of time. The description in the GI may match a typical Jangla produced today, but all the elements described may change over time. For example, the GI describes the design as using broche technique. But even handloom weavers frequently use lance technique in making jangla patterns to reduce labor time and costs. In terms of artisanship and durability lance woven designs are inferior to broche designs, as many weavers admitted in interviews, but does this mean a brochewoven fabric is authentic and a lance-woven one inauthentic? Clearly, such fine distinctions are not useful given the purpose of the GI, which most broadly construed is to improve the living standards of the weavers. Further, not all changes in practice are in the control of producers. For example interviews in villages surrounding Banaras city revealed that broche weaving, that requires the assistant of an apprentice (usually a young boy), has been abandoned due to fear of being charged with violation of child labor laws. Even though the law prohibits employment of a minor who is unrelated to the employer and exempts blood relatives, weavers reported harassment by police even when they worked with their own sons. 
To sum up, the object of a place-based IPR such as the GI is to prevent producers operating outside the indicated region from free-riding on the reputation of the indicated product. This requires some degree of definition on what constitutes the product to be protected. But in the case of the Banaras GI, the definition goes well beyond what it necessary and risks freezing of a dynamic tradition.

\section{Endogenous Technical Change and the GI}

The problematic nature of the Banaras GI is also revealed with respect to the question of powerlooms. Recall that an important motivation behind the GI was to protect the handloom product from powerloom competition. Thus only handloom products are granted GI protection. But the competition to the Banaras handloom does not originate only in machine-made products from China and elsewhere. Mechanized production has been emerging endogenously in Banaras as master-weavers invest capital accumulated via handlooms in powerlooms. The GI does not distinguish between powerloom products made in Banaras versus outside. It could be argued that powerlooms only proliferated in Banaras so that local manufacturers could compete with machine-made products coming from outside and that protecting the handloom market adequately would reduce the incentive to mechanize. But this should not be an argument against all technical change.

Although no definitive records are available, according to industry insiders the powerloom was introduced in Banaras in the 1970s and started to spread rapidly in the 1980s and 1990s. In interviews powerloom weavers emphasized that they have brought their imagination and skills to bear on the problem of creating a "Banarasi look" on powerlooms. One master-weaver who sells both handloom and powerloom products nationally and internationally was explicit on this issue. He noted, There is craftsmanship in Banaras. Even China can make silk, plain as well as design silk, but they did not succeed in mimicking the craftsmanship of Banaras. Since the powerloom has come to Banaras, we have given a lot of thought to developing it. (Field Interview, 6/13/2010) 
Of course, the master-weaver's response must be seen the context of the fact that he has made a fortune in powerlooms. But even small powerloom weavers (owning four or five looms at home) speak with pride about producing silk fabric on the machine and replicating handloom designs. A powerloom owner put forth this account:

The powerloom has been in Banaras since a long time but it has really become successful in the last ten years. Before that only plain cloth, simple designs, maybe one or two varieties, plain checks etc. were made. Today there are so many items even I cannot keep track of them. Saris are being made, dress material is being made. (Field Interview, 12/23/2009)

This has occurred in clear violation of existing legislation (pre-dating the GI) such as the Handloom Reservation Act (1985) that prohibits the mechanized production of certain types of fabric reserved for handloom. In the absence of effective implementation of the law, producers within Banaras and elsewhere have been able to free-ride on the reputation of Banaras handlooms without legal consequences. Since labor productivity is at least ten times higher than handlooms even on vintage powerlooms, and hourly wages are roughly the same in both cases, to the extent that powerloom fabric can be passed off as handloom, they can fetch higher prices in the market, thereby increasing profits for master-weavers and merchants (Basole 2014). The following testimony, by a handloom weaver, is typical of several more I was witness to, particularly from struggling handloom weavers.

The powerloom has affected us a lot. They sell machine made saris as Banarasi, they tell the customers, it is pure [English in original] Banarasi. The customer does not know the difference. What we weave with our hands, that is real Banarasi. (Field Interview 2/22/2010)

Despite a large number of news reports and stories in the local press on this issue, there exist no reliable sources of local statistics on the number of powerlooms operating in Banaras or the proportion of cloth in the market that is machine-made. The exact extent of passing-off is also unknown, but the common perception is that it is rampant. No official surveys or statistics exist, in part because the bodies that are most favorably placed to gather such data, the handloom producer cooperative societies, are themselves 
implicated in passing-off (Government of India 2008). Some traders openly admit to the practice. A proprietor of a sari showroom in the tourist-dominated area of Sarnath admitted to me that he sold powerloom cloth as handloom ("we say it is handmade") adding that customers usually cannot differentiate between the two. He also noted that the neighboring town of Mau (which incidentally has its own GI) is a major source of powerloom saris sold in Banaras as Banarasi Saris. On interviewing master-weavers in Mau, I discovered that machine made polyester cloth from Mau goes to Banaras where it is embroidered to give it a "Banarasi look" which means post-weaving embroidery of designs considered typical of Banaras.

The switch to mechanized production has brought about large changes in the product. Synthetic yarn has increasingly dominated on the machine and to compensate for the loss in sophistication of designs in moving from handlooms to powerlooms, another innovation in the industry has been the increasing use of post-weaving embroidery. The GI disqualifies all such new products from using the Banaras label because they displace the "traditional product." ${ }^{22}$ But the GI is not an outcome of community deliberations. It is an attempt by NGOs to preserve a craft and as the Director of the Weaver Service Center (a government body) in Banaras (a co-applicant of the GI), notes it "has come from outside, to preserve the identity."

The GI describes the stages of silk-based handloom production process in great detail. But today's "traditional methods" were innovations of yesterday. For example, one may wonder what would have happened if the GI had been around at the time of the introduction of the Jacquard mechanism in Banaras in the 1920s that greatly simplified the designing process and made it less labor intensive (Cort 1980; Dutta 2007). Would it have defined the Banarasi Sari as the pre-Jacquard version and declared the Jacquard produced fabric to be non-Banarasi? ${ }^{23}$ Being more aware of the history of their craft and, I would argue, not being motivated by a "preservationist" approach, weavers take a much more contingent and pragmatic view. Javed, a handloom weaver transitioning to powerloom production notes: 
Wherever the cloth comes from, even if its from China, once it is in the hands of the Banaras weavers, once they decorate it, it will sell as Banarasi only. Yes, the designs and the method of work have changed. Synthetic yarn has come, but the hand is not synthetic is it? The hand is Banarasi! When the designer draws he will draw Banarasi designs.

In other words Banarasi is what the people of Banaras do. My interviews suggest that weavers are far more concerned about cheating and bad faith, which they say damages the reputation of the industry, rather than the actual change in fiber or technology, which they regard simply as exigencies of craft practice. In other words, they do not show a desire to preserve a craft for its own sake, but dishonesty bothers them.

Of course poverty is the other major driver in the switch from hand to power. When asked if he regretted leaving his craft behind, one handloom-weaver turned powerloom operator said matter-of-factly, "If it doesn't give me enough to eat, what will I do loving it?" A powerloom master-weaver similarly noted: "When he is hungry he won't think, 'this is my traditional occupation.' On a full stomach you can remember all such things!"

\section{Political Economy and Powerlooms}

It is clear that fabric made in China or Surat and sold as Banarasi is a case of free-riding and passing-off. But is a powerloom-made sari made in Banaras a "Banarasi Sari?" Do weavers believe they are now producing a qualitatively different product undeserving of the name Banarasi? This question has not been raised publicly among the weavers themselves. Defenders of the handloom say that this is because the powerloom lobby has grown so strong in Banaras that it will not let such a question be raised. And indeed even Javed, who now has an interest in powerlooms, takes a more liberal view as outlined above, and is skeptical of the institutions who wrote the GI applications, agrees that many small handloom weavers would welcome the exclusion of powerloom saris from the category of authentic Banarasi Saris.

Stepping out of the preservationist paradigm, one can see that the question is not really one of technology. The reason the switch from hand to power in Banaras is controversial 
within the community is the industry's political economy. As one handloom weaver replied when asked how effective he thought a GI would be in preventing powerloom competition, "the powerful people are in powerlooms, the little people in handlooms, whose voice will be heard, you tell me? (Field Interview 2/22/2010) This succinctly captures the most likely outcome of the GI. Since those big producers who are best positioned to apply for and take advantage of the GI are the same ones who have enough capital to own powerlooms, it is likely that the GI will not be able to prevent passing-off, and instead serve as a front for larger powerloom master-weavers to hide behind, even as smaller powerloom weavers are punished for innovating.

The experience of other legislative mechanisms to protect the handloom market is a cautionary tale. Several of these, such as a law reserving certain items for production on handlooms as well as a certification mark for handloom products, have been subverted by the industry's more powerful actors. Ateek Ansari, a long-time industry observer, journalist and powerloom weaver, points out that powerloom producers have freely violated the national 1985 Handloom Reservation Act that reserved 22 items for manufacture on handlooms. And now, he adds,

...the government is trying to use patent law to protect this industry. This shows the government's intellectual bankruptcy. It is like trying to keep a tree alive by watering its leaves instead of its roots. It won't have any effect...(Field Interview 6/7/2010)

Taking another example, this time of the rug-mark that is supposed to indicate if childlabor has been used in making a carpet, Ansari noted that the mark has been widely misused and there is no effective policing of who is using it. Dr. Rajnikant of the Human Welfare Association, points out that the Handloom Mark, a certification mark which is two years older than the GI, has failed to take off in Banaras and " $90 \%$ of handloom weaver cooperative societies actually sell powerloom cloth" (Field Interview, 11/14/2009). A handloom master-weaver recounted a similar experience with the Silk Mark (a certification mark for silk fabrics). An "awareness workshop" did not appear to have any weavers, apart form him, in attendance. There was a discussion underway on 
rejecting goods on the basis of the absence of this mark, without significant participation from the artisan community (Field Interview, 5/2/2010).

A further problem for implementation of such legislation is that while powerful actors such as the larger master-weavers and traders may avail of the resulting premiums in the market even as they continue to violate its terms without punitive action, smaller weavers may be forced to infringe on the law out of economic necessity and risk being caught. For example, a government official in charge of enforcing the Handloom Reservation Act pointed out (on condition of anonymity) that in the eastern state of Orissa he had encountered small towels reserved for handlooms being manufactured on powerlooms. There was fierce competition in the market for this product and profit margins were low. The producers were poor weavers who did not have enough to eat. "How can I tell them it is a reserved product? How can I prosecute them for infringement?" he asked rhetorically. In such situations, he said, he looks the other way.

Perhaps because of his awareness of this reality, the Director of the Weaver Service Center (WSC) expressed a surprising opinion.

I think powerlooms will also be included under the GI. The only thing is that it should be made in this area. And its texture etc. should be preserved. You cannot use polyester and call it silk (Field Interview, 4/13/2010).

On the other hand, Rajnikant of the HWA was clear that the GI was a means to create a handloom niche, revive handloom products and enhance incomes of handloom weavers. Similarly Abhijit Das of UNCTAD noted that powerloom fabric is "not produced the way this fabric has been traditionally...produced" and their attempt is "to protect the traditional craft." (Field Interview 6/9/2010). Thus, even between the organizations that have initiated the GI there is lack of clarity on whether powerloom weavers from Banaras would be included or excluded.

In summary, the answer to, "should the GI exclude powerlooms" is not easy without extensive community-wide participatory processes that have been conspicuous by their 
absence. The answer to "will the GI be able to exclude powerlooms" seems to be "no" due to the prevailing power relations in the industry.

\section{Discussion and Conclusion}

The vast majority of the weavers of Banaras, the creators of its weaving tradition, are today living in poverty. The preservationist view diagnoses the problem as one of competition from machine-made cloth threatening a traditional craft and provides a legal solution: the Geographical Indication. In principle such an approach can be part of the solution. But the way it has been undertaken, it is problematic for two reasons.

First, we have seen that the Banaras GI puts forward rigorous standards to establish authenticity and has been developed with the intention of protecting the handloom market from powerloom competition. This impulse to protect the handloom does not come from the weavers. It comes from the custodians of craft who remove all criteria of craft authenticity from the midst of the artisan community. In the process it may punish those weavers who try to compete by means of technical change, since they are told they can no longer avail of their product's brand value. This approach chooses a "battleground where [the] strongest deployment (technology) [meets] the resisters' weakest deployment (tradition)" Grint and Woolgar (1997, p. 59). By choosing to fight over the terrain of tradition versus modernity the battle is lost before it is fought. By talking of preserving what exists we directly attack the very dynamism that has allowed artisanal knowledge to perform the function it does.

Second, legitimate political economy concerns such as the dominance of large masterweavers and traders over smaller own-work weavers as well as job-workers and loomless weavers (who constitute the majority of weavers) get deflected onto the craft preservation terrain because it is easier to legislate on what is authentic craft than to change the power relations in the industry. Most of the value-added will continue to accrue to master weavers and traders and misdirected State policy will continue to create powerful incentives for substitution of silk by synthetic fibers, substitution of broche weave by lance, hand by power. The GI does not change any of the structural factors that keep 
weavers poor. Instead of allowing innovation and improving the distribution of value within the industry, the GI will discourage innovation and allow (mal)-distribution of value.

To return to Ateek Ansari's metaphor, the GI may indeed only water the leaves, and not the root of the plant. What would constitute watering the roots? In other words, what would a more holistic policy approach look like?

First, wider consultations are needed and if necessary the GI must be broadened to include powerloom-made products from Banaras. A dual system that consists of a GI incorporating both hand and power produced saris (as long as they are made in Banaras), combined with a certification mark that distinguishes between the two, is a better solution. Such a method has been hinted at by others (Vinayan 2012, p. 62). A handloom mark can prevent encroachment of powerloom products on handlooms, while an inclusive GI will allow powerloom producers in Banaras to avail of the industry's reputation thereby increasing the demand for powerlooms and creating jobs in that sector. Such a scheme would be analogous to multiple certification systems such as "fair-trade," “organic," and region of origin used, among other products, for coffee.

This requires us to give up the "preservationist" view of craft and treat artisanal knowledge as dynamic. This does not mean lack of all standards and criteria of authenticity. These are needed preserve quality, reputation, and ecological sustainability of the product (Bowen and Zapata 2009). But the process by which these (evolving) criteria are decided is crucial for a good GI. An artisanal cluster embodies a knowledgecommons that is the result of generations of experimentation and innovation. Here, personal relationships such as master-apprentice relations are crucial to knowledge production and transfer (Polanyi 1962; Drahos 2011; Basole 2012). It is this cumulative store of knowledge that is marked by a GI. As such the IPR needs to accommodate, even encourage, the dynamism of such knowledge.

Lastly, Banaras, like many other informal artisanal industries, is in urgent need of collective bodies that represent the interests of ordinary artisans, in this case loomless and 
job-work weavers, who constitute the poorest and most numerous section of the industry. Without strong collective institutions at the local level, a more equitable sharing of value will not occur. As opposed to the preservationist view that valorizes the content of knowledge, the political economy perspective instead focused on the processes that create and sustain knowledge. Is it not the communities, their institutions, and the epistemic processes that have created these knowledge-commons marked by geographical indications that should be valorized and nurtured?

\section{Acknowledgements}

This work was funded by fellowships from the American Institute of Indian Studies (AIIS) and the Political Economy Research Institute (PERI). I thank my dissertation committee: J. Mohan Rao, James K. Boyce, Mwangi wa Githinji, and Ananya Vajpeyi. Jim Boyce, Rajesh Bhattacharya, Amy Cohen and Smita Ramnarain commented on this manuscript. I also thank Sunil Sahasrabudhey, Chitra Sahasrabudhey, Ehsan Ali Ansari, M. Ahmad Ansari, Pradeep Gond, Mohammad Aleem Hashmi, and Shilpi Suneja for their invaluable assistance during fieldwork. Responsibility for errors is mine. 


\section{Bibliography}

Addor, F. and Grazioli, A. (2002) 'Geographical indications beyond wines and spirits', The Journal of World Intellectual Property, 5(6), 865-897.

Ahmad, N. (2007) 'Globalization and the indigenous artisan economy: A case study of the Varanasi silk sari industry', Technical report, All India Artisans and Craftworkers Association.

Arewa, O. (2006) 'TRIPS and Traditional Knowledge: Local Communities, Local Knowledge, and Global Intellectual Property Frameworks (TRIPs Symposium)', Marquette Intellectual Property Law Review, 10(2), 156-180.

Aylwin, N. and Coombe, R.J. (2010) 'Marks indicating conditions of origin in rightsbased sustainable development', Human Rights, Development and Restorative Justice: An Osgoode Reader.

Banaras Bunkar Samiti, Human Welfare Association, Jt. Director Industries, Uttar Pradesh Handloom Fabrics Mktg. Co-op Federation Ltd., Eastern U.P Exporters Association, Banarasi Vastra Udyog Sangh, Director of Handlooms and Textiles U.P, Banaras Hathkargha Vikas Samiti, and Adarsh Silk Bunkar Sahkari Samiti Ltd (2009) ‘GI Application No. 99- Banaras Sarees and Brocades', Geographical Indications Journal 29, 30-65.

Basole, A. (2012) Knowledge, gender, and production relations in India's informal economy. Unpublished PhD thesis, Department of Economics, University of Massachusetts, Amherst, MA.

Basole, A. (2014) 'Informality and Flexible Specialization: Labour Supply, Wages, and Knowledge Flows in an Indian Artisanal Cluster', UMass-Boston Working Paper No. 2014-07. 
Basole, A. and Basu, D. (2011) 'Relations of Production and Modes of Surplus

Extraction in India, Part-II Informal Industry', Economic and Political Weekly, 46(15), 63-79.

Bismillah, A. (1986) Jhini Jhini Bini Chadariya [Hindi]. Rajkamal Prakashan, Delhi.

Bose, T. K. (2007) 'Globalization pushes Varanasi weavers to hunger and death', Report, People's Vigilance Committee for Human Rights, Varanasi.

Bowen, S. (2010) 'Development from within? The potential for Geographical Indications in the Global South', The Journal of World Intellectual Property, 13(2), 231-252.

Bowen, S. and Zapata, A.V. (2009) 'Geographical indications, terroir, and socioeconomic and ecological sustainability: The case of tequila', Journal of Rural Studies, 25(1), 108-119.

Brokensha, D., Warren, D. and Werner, O (1980) Indigenous Knowledge Systems and Development, University Press of America.

Broude, T. (2005) 'Taking Trade and Culture Seriously: Geographical Indications and Cultural Protection in WTO Law', U. Pa. J. Int'l Econ. L., 26, 623.

Chan, A. S. (2011) 'Competitive Tradition: Intellectual Property and New Millennial Craft', Anthropology of Work Review, 32(2), 90-102.

Cort, C. C. (1980) 'The Brocades of Banaras- An Analysis of Pattern Development in the 19th and 20th Centuries', The Bulletin of the Needle and Bobbin Club, 63(1), 3-35.

Cottier, T. and Panizzon, M. (2004) 'Legal perspectives on traditional knowledge: The case for intellectual property protection', Journal of International Economic Law, 7(2), 371-399. 
Dagne, T. (2010) 'Law and policy on intellectual property, traditional knowledge and development: Legally protecting creativity and collective rights in traditional knowledge based agricultural products through Geographical Indications', The Estey Centre Journal of International Law and Trade Policy, 11(1), 68-117.

Das, K. (2006) 'International Protection of India's Geographical Indications with Special Reference to “Darjeeling” Tea', The Journal of World Intellectual Property, 9(5), 459495.

Das, K. (2007) 'Protection of Geographical Indications: An overview of select issues with particular reference to India', Center for Trade and Development, Working Paper 8.

Das, K. (2010) 'Prospects and challenges of Geographical Indications in India', The Journal of World Intellectual Property, 13(2), 148-201.

de Neve, G. (2005) 'Weaving for IKEA in South India: Subcontracting, Labour Markets and Gender Relations in a Global Value Chain', in J. Assayag and C.J. Fuller (eds.) Globalizing India: Perspectives from Below, Anthem Press, pp. 89-118.

Dickie, V. A. and Frank, G. (1996) 'Artisan occupations in the global economy: A conceptual framework', Journal of Occupational Science, 3(2), 45-55.

Downes, D. (1997) 'Using intellectual property as a tool to protect traditional knowledge: Recommendations for next steps', CIEL Discussion Draft.

Drahos, P. (2011) 'When cosmology meets property: indigenous people's innovation and intellectual property', Prometheus, 29(3), 233-252.

Dutta, A. (2007) The Bureaucracy of Beauty: Design in the Age of its Global Reproducibility, Routledge, New York. 
Field, L. (2009) 'Four kinds of authenticity? Regarding Nicaraguan pottery in Scandinavian museums', American Anthropologist, 36(3), 507-520.

Finger, J. M. and Schuler, P.E. (2004) Poor Peoples Knowledge: Promoting Intellectual Property in Developing Countries, World Bank and Oxford University Press.

Fowler, B. (2004) 'Preventing Counterfeit Craft Designs', in J.M. Finger and P. E. Schuler (eds) Poor People's Knowledge: Promoting Intellectual Property in Developing Countries, World Bank and Oxford University Press, pp. 113-131.

Frankel, S. (2011a) 'Attempts to protect indigenous culture through free trade agreements', in C. Graber, K. Kuprecht and J. Lai (eds.) International trade in indigenous Cultural Heritage, Edward Elgar.

Frankel, S. (2011b) 'The mismatch of geographical indications and innovative traditional knowledge', Prometheus, 29(3), 253-267.

Gade, D. W. (2004) 'Tradition, territory, and terroir in French viniculture: Cassis, France, and appellation controlee', Annals of the Association of American Geographers, 94(4), 848-867.

Gervais, D. (2005) 'Traditional Knowledge and Intellectual Property: A TRIPSCompatible Approach', Mich. St. L. Rev. Spring 2005, 137-166.

Gopalakrishnan, N. S., Nair, P. S. and Babu, A. K. (2007) 'Exploring the relationship between GIs and TK: an analysis of the legal tools for the protection of GIs in Asia', ICTSD Programme on Intellectual Property Rights and Sustainable Development, International Centre for Trade and Sustainable Development, Geneva, Switzerland. Government of India (1999) The Geographical Indication of Goods (Registration and Protection) Act, 1999. The Gazette of India Extraordinary. 
Government of India (2008) 'Diagnostic study of the handloom silk cluster, Varanasi (Uttar Pradesh)', Development Commissioner of Handlooms, Ministry of Textiles.

Grint, K. and S. Woolgar (1997) The Machine at Work: Technology, Work and Organization, Polity Press.

Gupta, A. K. (2007) 'Grassroots to global: Online incubation of grassroots innovations based enterprises', IIM-Ahmedabad Working Paper.

Haynes, D. E. (2012) Small Town Capitalism in Western India: Artisans, Merchants and the Making of the Informal Economy, 1870-1960, Cambridge University Press, Cambridge, UK.

Hughes, J. (2006) 'Champagne, Feta, and Bourbon: the spirited debate about geographical indications', Hastings LJ, 58, 299-386.

Jain, L. C. (1983) 'Handlooms face liquidation: Powerlooms mock at Yojana Bhavan', Economic and Political Weekly, 18(35), 1517-1526.

Knorringa, P. (1999) 'Artisan labour in the Agra footwear industry: Continued informality and changing threats', Contributions to Indian sociology, 33(1-2), 303-328.

Kumar, N. (1988) The Artisans of Banaras: Popular Culture and Identity, 1880- 1986, Princeton University Press, Princeton, NJ.

Liebl, M. and T. Roy (2004) Handmade in India: Traditional Craft Skills in a Changing World, in Finger and Schuler (eds.) Poor People's Knowledge: Promoting Intellectual Property in Developing Countries, pp. 53-73. World Bank and Oxford University Press.

Littrell, M. A. and Dickson, M. A. (1999) Social responsibility in the global market: Fair trade of cultural products. Sage Publications. 
Martens, P. (2012) 'Can Traditional Knowledge Owners and Producers in Developing Countries Use Geographical Indications for Protection and Economic Development Gain?' Paper presented at Society of International Economic Law (SIEL),3rd Biennial Global Conference.

Mathur, A. (2003) 'Who Owns Traditional Knowledge?' Economic and Political Weekly, 38(42): 4471-4481.

Nash, J. C. (ed.) (1993) Crafts in the world market: The impact of global exchange on Middle American artisans. SUNY Press.

Polanyi, M. (1962) Personal Knowledge: Towards a Post-Critical Philosophy, Harper and Row, New York.

Raman, V. (2010) The Warp and the Weft: Community and Gender Identity among Banaras Weavers, Routledge, New Delhi.

Raman, V. (2013) Entangled Yarns: Banaras Weavers and Social Crisis, Indian Institute of Advanced Study, Shimla.

Rangnekar, D. (2010) 'The law and economics of Geographical Indications: Introduction', The Journal of World Intellectual Property 13(2), 77-80.

Rashid, O. (2014) 'WhatsApp Worsens Varanasi Weavers' Woes', The Hindu, 30 ${ }^{\text {th }}$ March.

Roy, T. (1998) 'Development or Distortion? “Powerlooms” in India, 1950-1997,' Economic and Political Weekly, 33(16), 897-911.

Sahasrabudhey, S. and Sahasrabudhey C. (2001) The Lokavidya Standpoint [Hindi], Lokavidya Pratishtha Abhiyan, Varanasi. 
Scott, J. C. (1998) Seeing Like a State: How Certain Schemes to Improve the Human Condition Have Failed, Yale University Press, New Haven, CT.

Scrase, T. J. (2003) 'Precarious production: globalisation and artisan labour in the Third World', Third World Quarterly, 24(3), 449-461.

Sillitoe, P., Bicker, A. and Pottier, J. (Eds.). (2002). Participating in development: approaches to indigenous knowledge (Vol. 39). Psychology Press.

Singh, B. (2011) 'Weavers want hike in import duty on Chinese silk fabric', The Times of India, $15^{\text {th }}$ March.

Soam, S. K. (2005) 'Analysis of prospective geographical indications of India', The Journal of World Intellectual Property, 8(5), 679-704.

Srinivasulu, K. (1996) '1985 Textile Policy and Handloom Industry: Policy, promises and performance.' Economic and Political Weekly, 31(49), 3198-3206.

Steiner, C.B. (1999) 'Authenticity, Repetition, and the Aesthetics of Seriality: The Work of Tourist Art in the Age of Mechanical Reproduction' in R.B. Phillips and C.B. Steiner (eds.) Unpacking culture: Art and commodity in colonial and postcolonial worlds. University of California Press, Berkeley. CA, pp. 87-103.

Subbiah, S. (2004) 'Reaping what they sow: The Basmati rice controversy and strategies for protecting traditional knowledge', Boston College International and Comparative Law Review 27, 529-559.

Sunder, M. (2007) 'The invention of traditional knowledge', Law and contemporary problems, 97-124. 
Varman, R. and Chakrabarti, M. (2006) Case Studies on Industrial Clusters: A Study of Kanpur Leather and Footwear, Varanasi Silk Saree, and Moradabad Brassware Clusters, Department of Scientific and Industrial Research, Government of India, Technical Report.

Varman, R., \& Chakrabarti, M. (2011) 'Notes from small industry clusters: making sense of knowledge and barriers to innovation', AI and Society, 26(4), 393-415.

Venkatesan, S. (2009) Craft Matters: Artisans, Development and the Indian Nation, Orient Blackswan, New Delhi.

Vinayan, S. (2012) 'Intellectual Property Rights and the Handloom Sector: Challenges in Implementation of Geographical Indications Act', Journal of Intellectual Property Rights, 17, 55-63.

Warren, D. M., Slikkerveer, L. J. and Brokensha, D. (1995) The cultural dimension of development: Indigenous Knowledge Systems. Intermediate Technology, London, UK.

Woytek R., Shroff-Mehta, P. and Mohan, P.C. (2004) Local Pathways to Global Development. Knowledge and Learning Group, Africa Region, World Bank. 


\section{Notes}

\footnotetext{
${ }^{1}$ This is closely connected to the discourse on "fair trade" as well as "cultural products." Such trade is exemplified by a store such as Ten Thousand Villages. See case studies in Littrell and Dickson (1999)

${ }^{2}$ A complete list of awarded GIs along with the full application for each one is available in various issues of the GI Journal here: http://ipindia.nic.in/girindia/ (accessed August 2014)

${ }^{3}$ The word "Banarasi" is an adjective meaning "from Banaras." A sari (saree) is a piece of fabric, usually 6 meters by 1 meter, wrapped as a garment.

${ }^{4}$ Fieldwork was conducted in the weaver localities in Banaras city and surrounding villages as well as the nearby weaving towns of Mau (100 km north) and Mubarakpur (120 km north-west).
}

${ }^{5}$ The Doha round of the WTO called for TRIPS council to examine the compatibility of TRIPS with TK (Mathur 2003; Gervais 2005). Debates undertaken through WIPO, UNCTAD, Convention of Biological Diversity (CBD) and WTO have attempted to grapple with the complex issue. See Drahos (2011).

${ }^{6}$ See Gopalkrishnan et al (2007) for a detailed account of the genesis of the GI. The most recent international agreement on this issue, which also introduced the term Geographical Indication for the first time, is the WTO Agreement on Trade Related Aspects of IPRs (TRIPs) which defines GIs as

"indications that identify a good as originating in the territory of a Member, or a region or locality in that territory, where a given quality, reputation or other characteristic of the good is essentially attributable to its geographical origin." (TRIPs Article 22.1)

The TRIPs agreement has the widest reach and goes further than the previous agreements in that allowance was made for "reputation" separate from the quality or characteristic of a good (Gopalkrishnan et al 2007, p. 14). So even in the absence of the contribution of any natural factors (such as soil or climate) the reputation clause can ensure that artisanal products qualify for GI protection.

${ }^{7}$ The Indian definition is broader than the TRIPs definition in specifying that a GI means an indication which identifies such goods as agricultural goods, natural goods or manufactured goods as originating, or manufactured in the territory of country, or a region or locality in that territory, where a given quality, reputation or other characteristic of such goods is essentially attributable to its geographical origin and in case where such goods are manufactured goods one of the activities of either the production or of processing or preparation of the goods concerned takes place in such territory, region or locality as the case may be. (Government of India 1999)

${ }^{8}$ Fowler (2004) recounts an interview with Andy Abeita, president of the Council for Indigenous Arts and Culture, in which Abeita reveals how a corporation and a town named "Zuni" (a Native American nation) were formed in the Philippines. Goods manufactured in this town were sold in the United States with "Made in Zuni" stamps. Abeita also notes that in most cases it is Americans who take the design overseas to reproduce them cheaply, and to smuggle them back as originals.

${ }^{9}$ Hughes (2006, p. 17):

To the degree that European-style appellations law is less prone to innovation and more prone to safeguarding the status quo, we need to recognize this is not a flaw in appellations law; it is a characteristic, if not the goal. (p. 17)

Frankel (2011b, p.261) goes so far as to say that GIs are the wrong tool if the aim of protecting TK is also to support innovation, because they are status-quoist.

${ }^{10}$ Of course, if market forces are strong enough, producers may forsake GI protection (Broude 2005, p. 665). Champagne producers in France have moved significantly away from production practices of the $17^{\text {th }}$ and $18^{\text {th }}$ centuries. The claim to exclusivity now results from their reputation more than their adherence to those practices (Frankel 2011b, p. 261). 
${ }^{11}$ Dickie and Frank (1996, p. 52)

The stone carvers of Membrillo, Panama have worked in their medium for only the past 20 years or so, following the discovery of a vein of soapstone in a riverbank in the vicinity. One of their most popular carving subjects is the elephant, although no one in their cooperative has ever seen an elephant. Why elephants? Because the Asian tourists who come to the El Valle de Antn market or the artisanal shops buy them for good luck.

As Frankel (2011b, p.262) puts it, "traditional knowledge is traditional because of its longevity, not because it is closed to development." In the Indian context, Anil Gupta of the Honeybee Network has been arguing the case for little known rural innovators (Gupta 2007). Even the WIPO notes that "much TK is not ancient or inert, but is a vital, dynamic part of the contemporary lives of many communities today." (WIPO 2008, p.6)

${ }^{12}$ Several studies since the 1970s have attempted to explain the rapid increase in share of cloth production by powerlooms and the concomitant stagnation in the share of handloom cloth (Jain, 1983; Srinivasulu, 1996; Roy 1998). State policy favoring the decentralized (small-scale) sector over the large factory (textile mill) sector, productivity advantages of power over hand, increasing intensity of capital-labor conflict in the mill sector, and access to a cheap labor-force in the informal sector have together conspired to bring about this result. Simultaneously, handloom weavers with enough capital have set up powerlooms to benefit from increased productivity. Haynes (2012) notes that the introduction of mechanization in the Indian weaving industry should be seen as a slow process of internal change.

${ }^{13}$ Between Kumar (1988) and Raman (2010) there was one government-sponsored report and one NGO-led study dedicated to Banaras (Ahmad 2007; Government of India 2008) and one study that includes Banaras among three industrial clusters (Varman and Chakrabarti 2006, 2011).

14 "Hunger forces artisans to commit suicide", The Times of India, Nov 4, 2009.

${ }^{15}$ Chinese silk fabric imports increased four-fold between 2005 and 2010 (from about 400,000 meters to 1.6 million meters of silk fabric per day) (Singh 2011). Over this same period Chinese silk yarn, a key input to the industry, became expensive. This was because over roughly a decade from 2002 to 2010 duty levied on imported Chinese silk yarn remained at 30\% while duty on imported silk fabric was reduced from $30 \%$ to $10 \%$ (Ministry of Textiles, Sericulture Division). Emphasizing the dependence of the industry on imported yarn, Badruddin Ansari, the Chairman of the UP Handloom Co-op Federation, noted that domestic silk yarn production is 16,000 metric tons while the demand is 28,000 metric tons (Field Interview, 6/11/2010). Also see: "Import Duty on Chinese Silk Yarn Needs Revision", The Times of India, Nov 20, 2009.

16 'Patenting Brocade Need of the Hour', The Times of India May 13, 2006.

${ }^{17}$ These organizations are Banaras Bunkar Samiti (BBS), Human Welfare Association, Joint Director Industries (Eastern Zone), Director of Handlooms and Textiles U.P., Eastern U.P Exporters Association, Banarasi Vastra Udyog Sangh, Uttar Pradesh Handloom Fabrics Mktg. Co-op Federation Ltd, Banaras Hathkargha Vikas Samiti, and Adarsh Silk Bunkar Sahkari Samiti Ltd.

${ }^{18}$ Although no scholarly work exists on this subject, it is commonly acknowledged that the cooperative societies set up in Banaras, that were intended to benefit ordinary weavers, have been co-opted by larger master weavers and often function merely as fronts for a putting-out operation. The fake co-op, whose chairman is a master weaver and whose "members" are either fictitious names or actual weavers who are often job-workers for the same master, is such a part of local lore that it is the central premise of a novel on the Banaras weavers (Bismillah 1986).

${ }^{19}$ Field Interview 4/7/2010. This account matches the procedure outlined in The Geographical Indications of Goods (Registration and Protection) Rules, 2002 published in the Gazette of India, Extraordinary, Part II Section 3, Sub-Section (i) Extraordinary, Dated 8th March, 2002 
${ }^{20}$ For example, I was in attendance at a meeting of the weavers belonging to the BBS when an article was read out reporting on the GI awareness-building meeting held at a five-star hotel in Banaras. In the article Dr. P. Nayak, Director of Market Research for the Indian Textile Ministry is quoted as saying, "Only those saris will be considered Banarasi which have been made by producers who have the GI certificate."

${ }^{21}$ I thank Amy Cohen for pointing this out.

${ }^{22}$ A study commissioned by the Development Commissioner (Handlooms), Government of India (2008, p. 5) laments that post-weaving embroidery

...is undermining the significance of exquisite weave in the traditional aesthetic consciousness. This shift from weave to non-weave ornamentation... may not be temporary and poses a serious, long-term threat to the prospects of higher-end Banarasi saree.

${ }^{23}$ The introduction of the Jacquard mechanism in the early 20 th century was, at that time, a substantial change in technique (Dutta 2007). Though no primary sources are available, Dutta (2007) reports on the basis of colonial documents that the introduction of the Jacquard was met with resistance for several years, before it became generalized in Banaras. 